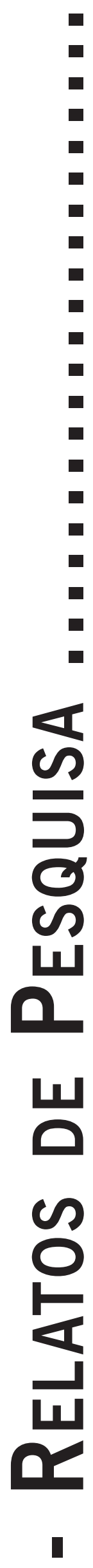




\title{
IMPACTOS DA AÇÃO DE AGENTES REDUTORES DE DANOS SEGUNDO PROFISSIONAIS DA REDE SUS
}

\author{
Impacts of Reduction Action According to SUS Professionals \\ Acción de Impacto Agentes de Reducción de Daños segundos Profesionales en el SUS \\ Ricardo Wagner Machado da Silveira \\ Paulo Otávio Andrade Oliveira D’Tôlis
}

\begin{abstract}
Resumo: Este trabalho discorre sobre os impactos causados pela ação de agentes redutores de danos (rds) na rede pública de saúde da cidade de Uberlândia-MG, de acordo com a perspectiva de profissionais que compõem parte desta rede de atenção em saúde. O método utilizado para a coleta de dados desta pesquisa qualitativa é a aplicação de entrevistas semiestruturadas nesses profissionais e, para análise dos dados, foi escolhida a Análise de Conteúdo. Os resultados apontam que o trabalho dos rds na Rede de Saúde Pública de Uberlândia-MG contribui para que os serviços de saúde incorporem em sua rotina, práticas relacionadas com as diretrizes da reforma psiquiátrica, o que gera como impacto mudanças nas suas estratégias de funcionamento e na relação com que os usuários de drogas estabelecem com elas.
\end{abstract}

Palavras-chave: Redução de danos; Reforma psiquiátrica; Políticas de saúde.

\begin{abstract}
The purpose of this study is to discuss the impacts caused by damage reduction agents (rds) work in the city of Uberlândia-MG, according to the perspective of professionals who are part of the Attention network of the county. The method used to collect the data of this qualitative research was interviews with these professionals and, for the analysis of the data, was used the content analysis. The results shows that the work of the reduction agents in the Public Health Network in UberlândiaMG contributes to the incorporation of guidelines from the psychiatric reform in the routine of the service, that generates strategy chances in the operations and in the relationship that drug user established with it.

Keywords: Damage-reduction; Psychiatric reform; Health policies.

Resumen: El propósito de este estudio es analizar los impactos causados por agentes de reducción de daños (rds) que trabajan en la ciudad de Uberlândia-MG, según la perspectiva de los profesionales que forman parte de la red de atención de la provincia. El método utilizado para recoger los datos de esta investigación cualitativa es entrevistas con estos profesionales y, para el análisis de los datos, se utilizó el análisis de contenido. Los resultados muestran que el trabajo de los agentes de reducción en la Red de Salud Pública en Uberlândia-MG contribuye a la incorporación de las directrices de la reforma psiquiátrica en la rutina del servicio, que genera oportunidades de estrategia en las operaciones y en la relación que el usuario de drogas establecido con él.

Palabras-clave: Reducción de daños; La reforma psiquiátrica; Las políticas de salud.
\end{abstract}

\section{Introdução}

Este trabalho é parte dos resultados de uma pesquisa de iniciação científica que investigou os impactos da implantação e consolidação da política e das práticas de Redução de Danos (RD) em Uberlândia, a pesquisa foi coordenada por um docente do Instituto de Psicologia da Universidade Federal de Uberlândia. Para tanto, foram investigados os impactos da $\mathrm{RD}$ sob o ponto de vista dos usuários e seus familiares; sob o ponto de vista dos agentes redutores de danos (rds) e sob o ponto de vista de outros profissionais da rede que trabalham ou trabalharam com os rds.

Neste artigo iremos discorrer sobre os impactos da ação de rds na rede pública de saúde da cidade de Uberlândia-MG, de acordo com a perspectiva de profissionais que compõem parte desta rede de atenção em saúde e que trabalham ou trabalharam com os rds. Nosso objetivo neste caso é conhecer a repercussão do trabalho do rd junto aos profissionais, equipes e serviços de saúde no tratamento dos usuários que fazem uso de álcool e outras drogas. Com isso pretendemos dar maior visibilidade às experiências de implantação da RD na rede com a apresentação de resultados concretos que podem levar a melhores condições para uma gestão planificada e sistêmica da rede de serviços de atenção em saúde para pessoas que fazem uso de álcool e outras drogas, considerando evidentemente as especificidades de cada serviço de saúde. Ou seja, este estudo pretende ser competente para auxiliar nos processos clínicos e de gestão necessários para a consolidação da política e das práticas de RD na rede.

O método utilizado para a coleta de dados desta pesquisa qualitativa foi a realização de entrevistas semiestruturadas com 21 profissionais que atuam nos serviços de saúde de Uberlândia, na tentativa de compreender 
suas percepções a respeito do trabalho dos rds e da resolutividade ou não alcançada por tais agentes de saúde. Os dados foram tratados através da análise de conteúdo proposta por Bardin (2009) e os resultados são apresentados em duas categorias: a) Modificações nas formas de funcionamento dos serviços de saúde e b) Mudanças na forma com que se estabelecem as relações entre serviços, profissionais e usuários.

Para tanto, inicialmente faremos um resgate histórico da política de RD no Brasil, em seguida iremos tratar desta política em Uberlândia; em seguida abordaremos algumas características do trabalho dos rds e por fim apresentaremos os dados e análises feitas das entrevistas realizadas com os profissionais da rede de saúde da cidade que tiveram experiências de trabalho em equipe com os rds e/ ou que tiveram a oportunidade de conhecer na prática a política de RD.

\section{Sobre a história da Redução de Danos (RD) no Brasil}

Os estudos das primeiras décadas do século XX demonstram que as questões referentes às drogas no Brasil eram mais relacionadas com a segurança pública do que com a saúde, e as ações perpetradas a respeito enfatizavam a repressão, ao invés da prevenção. Já na primeira metade dos anos 80, houve uma diminuição ainda maior dos investimentos em Saúde Pública, e a lacuna que já existia na assistência aos usuários de drogas foi ampliada, o que favoreceu a criação de comunidades terapêuticas não governamentais e de caráter religioso. Já na segunda metade da década de 80 , devido à epidemia de AIDS, ao aumento no abuso das substâncias e à pressão de movimentos sociais, as políticas de combate às drogas começaram a falir e estratégias de prevenção ganharam espaço, sendo elas: controle de bancos de sangue, ensinos de formas mais saudáveis de se fazer sexo, testagens e aconselhamentos. Tudo isso serviu como base para as estratégias relacionadas à Redução de danos (RD). (Machado e Boarini, 2013)

...a ideia de acabar com o uso de drogas entre os seres humanos é irreal, pois, para isso acontecer seria necessário modificar a própria condição ontológica do homem (a tarefa intransferível de cuidar do seu próprio existir) (Sodelli, 2010, p. 643)

No livro “Clínica Peripatética” de Lancetti (2007), há uma entrevista do autor com Domiciano Siqueira, membro da primeira equipe de agentes redutores de danos (rds) no Brasil. A esse respeito, tal profissional narra, entre outros, que os trabalhos começaram em 1995, quando um projeto sobre $\mathrm{RD}$ foi escrito por membros da Secretária de Saúde e da Secretária de Meio Ambiente do Estado do Rio Grande do Sul e enviado à Brasília para análise.
Após sua aprovação, ocorreram diversas reuniões para discutir as atividades que seriam realizadas, e uma primeira prática aconteceu no I Congresso Brasileiro de Prevenção das Doenças Sexualmente Transmissíveis/AIDS, em Salvador, em 1996.

Nos anos seguintes, a política da RD evoluiu: por meio da Lei $n^{0} 11.343 / 2006$, a Redução de Danos foi regulamentada como uma política que atua nas instituições por meio das práticas do SUS (Sistema Único de Saúde). Já em 2012, a portaria $\mathrm{n}^{0} 123$ estabeleceu as diretrizes e normas para a organização da Atenção Básica em Saúde, as quais incluíram os métodos para aplicação dos PCRs (Projetos Consultório de Rua) (Brasil, 2012). Assim, foi definido que uma Equipe de RD deveria ser composta por, no mínimo, duas pessoas com nível superior e duas com nível médio, as quais devem realizar ações em parceria com as Unidades Básicas de Saúde (UBS), os Centros de Atenção Psicossocial (CAPS) e outros serviços de atendimento urgente (Pacheco, 2013).

A RD pode ser entendida como uma estratégia de cuidado em saúde que tem como objetivo minimizar os agravantes e malefícios à saúde relacionados e desencadeados pelo consumo de drogas. Essa política tem seus princípios básicos de atuação pautados nas diretrizes do SUS, que são Universalidade, Integralidade e Equidade, além de visar participação social e autonomia do sujeito ao longo do tratamento.

A atual política de saúde mental estabelecida pelo Ministério da Saúde se alicerça nos princípios e práticas da Reforma Psiquiátrica e da Luta Antimanicomial, e utiliza a Redução de Danos como estratégia de cuidado, tal como Souza, Kantorsi, Gonçalves, Mielke e Guadalupe (2007) explicam. A esse respeito, é importante salientar sobre reverberações da reforma psiquiátrica. A reforma psiquiátrica visa consolidar uma rede de assistência em saúde mental que utiliza práticas psicossociais nas próprias comunidades como método para propiciar o tratamento do sujeito em sofrimento psíquico e sua organização nos territórios aonde vive, sempre lutando pela garantia dos direitos humanos e da cidadania (Gonçalves \& Sena, 2001). Em outras palavras, ela vai em direção oposta às práticas de isolamento e reclusão que aconteciam em diversos hospitais psiquiátricos no Brasil, tal como o de Barbacena, que foi marcado pelas condições precárias e desumanas que os internados experimentavam (Arbex, 2013).

A partir desta reforma, as pessoas acometidas por transtornos mentais, vícios, sofrimentos profundos, especialmente aquelas que foram simplesmente abandonadas por seus familiares, se livraram do enclausuramento manicomial e passaram a ocupar os cenários urbanos, a estar à vista e na presença de todos.

Entretanto, esse movimento acabou criando novas demandas, pois mesmo com os avanços e conquistas da Luta Antimanicomial, as mudanças propostas têm um árduo caminho a percorrer que vai da desospitalização à desinstitucionalização, e isso depende de um tempo 
histórico que promova mudanças na cultura. Assim, as pessoas com transtornos mentais e usuários de drogas continuaram e continuam a ser rotineiramente vítimas de preconceitos, violências e repressões, já que são percebidas como se fossem estranhas à ordem social. Se a sociedade contemporânea é feita para pessoas que tem o que comprar ou o que vender, caso alguém não consiga fazer isso, ela ficará de fora do sistema, à margem, marginalizada, em situação de vulnerabilidade e risco.

A partir deste contexto que se pode pensar o que é a $\mathrm{RD}$ e como ela passa a ser uma urgência política e pragmática, pois ela se trata de uma política para aumentar a qualidade de vida das pessoas em tratamento (Brasil, 2014). Assim, a RD visa tentar sanar algumas das demandas que surgiram pós reforma psiquiátrica, como a efetivação de novas práticas nos tratamentos e na tentativa de realizar uma mudança na relação da sociedade e das instituições com os usuários de drogas e com as drogas. Em suma, tais elementos demonstram que a $\mathrm{RD}$ segue os princípios da reforma psiquiátrica, já que visa fortalecer a rede em saúde mental com práticas psicossociais na própria comunidade.

Vale ressaltar que, na realidade não há oposição entre abstinência e redução de danos. A RD apenas visa aumentar a gama de intervenções que podem ser realizadas, contemplando assim mais pessoas, visto que, segundo Brasil (2014), apenas 20\% dos usuários conseguem ficar abstinentes, inviabilizando assim, o tratamento de $80 \%$ deles.

Ao chegarmos por meio da fenomenologia existencial à compreensão sobre a impossibilidade de mudar a condição existencial do homem, e consequentemente, a sua disposição em relação ao uso de drogas, identificamos na abordagem da redução de danos um terreno fértil para firmarmos um novo objetivo preventivo: reduzir vulnerabilidades ao uso nocivo de drogas (Sodelli, 2010, p. 643).

Em suma, ao se pensar em Redução de Danos é importante sempre trazer à baila um pressuposto básico: 0 oposto da droga não é a abstinência, mas sim, a liberdade (Brasil, 2014).

\section{0 que fazem os RDs?}

Nos dias atuais, a RD é parte integrante das diretrizes de tratamentos determinadas pelo Ministério da Saúde (Brasil, 2005). Diversas orientações para boas práticas em saúde tem sido tem sido veiculadas nos dispositivos de Educação Permanente em Saúde para capacitação dos profissionais da rede, como por exemplo as prescritas no guia de saúde mental elaboradas para agentes comunitários, auxiliares e técnicos de enfermagem (Brasil, 2014), que explicam que a estratégia da $\mathrm{RD}$ vai além da troca de seringas, com destaque para a escuta atenta, o acolhimento, o vínculo, o acompanhamento ao longo do tempo e a percepção integral do sujeito. Além do que, a construção do projeto terapêutico singular deve ser definida sempre em conjunto com o usuário, respeitando suas liberdades individuais.

As práticas da RD são escolhidas junto com os usuários e tem como o objetivo diminuir os riscos relacionados à exposição decorrente do uso de drogas. Ela não visa, necessariamente, fazer com que a pessoa deixe de usar drogas, mas sim criar uma aproximação com o usuário de modo humanizado, respeitando os desejos da pessoa e acolhendo-a, independentemente de ela seguir as recomendações do tratamento, sem impor obrigações ou construir hierarquias. Ela aparece, basicamente, como uma aproximação com um grupo que acredita não possuir lugar na sociedade, utilizando novas técnicas de intervenção, que respeitem as decisões do outro. (Lancetti, 2007)

Os rds devem adotar uma postura ética, respeitosa e acolhedora, de modo que os usuários procurem se vincular aos serviços de saúde e se sintam bem nos mesmos, pois esta é uma das principais demandas que perpassam a criação da RD, considerando o baixo índice de adesão aos tratamentos hegemônicos (Brasil, 2014).

Dessa forma, os rds têm como algumas de suas funções, a disponibilização de Kits de redução de danos, os quais incluem seringas, agulhas, frascos de água destilada, recipientes para diluição e compressas com álcool e ações como trocas de filtros de cachimbos (Brasil, 2001; Fonseca \& Bastos, 2005), a realização de projetos com crianças e adolescentes em situação de risco (Brasil, 2001), o fornecimento de informações sobre saúde, o fortalecimento do vínculo da unidade de saúde com o usuário e a ampliação do acesso ao serviço disposto.

\section{A RD em Uberlândia}

Em entrevista com as coordenadoras dos projetos de RD em Uberlândia-MG, Faria (2014) vislumbra um pouco da história desta política na cidade e explica que sua implantação, em termos burocráticos, ocorreu em 2010, com a abertura de dois editais de contratação pelo Ministério da Saúde (MS) - Escola de RD e Consultório de Rua -. É evidente que alguns profissionais da rede, particularmente os que trabalhavam no Centro de Atenção Psicossocial - álcool e outras drogas (CAPS ad), já vinham se reunindo e amadurecendo projetos de implantação da RD na cidade. Nos primeiros editais, foram contratados cinco rds, dois para atuar no Consultório de Rua e três na Escola de rds. Houve, então, a criação de mais uma Escola de RD e, até 2014, as escolas contavam com vinte e um alunos cada, sendo contabilizadas 5.309 pessoas atendidas pelos Consultórios de Rua e 5.650 pelas duas Escolas de Redução de Danos.

Com o passar do tempo, os rds passaram a ser reconhecidos como agentes de saúde da rede e possuem funções 
estabelecidas em contratos temporários firmados com a Prefeitura da cidade, com carga horária de 20h semanais, supervisões e práticas em saúde, tendo um tempo médio de vínculo com a profissão permeando de seis meses a dois anos e meio, possuem escolaridade variada, faixa etária oscilando entre 21 e 40 anos, têm experiências profissionais díspares e trabalham junto aos serviços de saúde da cidade. Em 2015, finalmente foram abertas 18 vagas para agentes redutores de danos na rede SUS da cidade, através de concurso público feito pela Secretaria Municipal de Saúde da cidade.

\section{0 que queremos? Porque estudar os impactos da rd na rede?}

Uma breve revisão de literatura é suficiente para revelar ao leitor que as formas de tratamento e cuidado em saúde com pessoas que fazem uso prejudicial de drogas estão mudando nos últimos anos. Mesmo que o modelo hegemônico para este tipo de tratamento conceba a saúde segundo concepções jurídicas, psiquiátricas e religiosas, cada vez mais aparecem trabalhos que demonstram a utilização de uma nova política neste segmento, com uma perspectiva diferente no cuidado em saúde oferecido aos usuários, qual seja, a RD (Passos \& Souza, 2011).

A RD, quando efetivada na prática, possui como uma de suas características mais singulares, a capacitação de rds que têm uma atuação no sistema de saúde diferente dos demais profissionais, com novas funções e práticas, tornando-se assim uma nova referência nas estratégias de cuidado, se relacionando com os outros agentes de saúde e com a própria instituição, o que causa uma série de repercussões.

Dessa forma, o estudo dos impactos das ações dos rds faz-se necessário, pois permite conhecer mais sobre como o seu trabalho repercute no funcionamento dos serviços de saúde e no tratamento dos usuários. Além de dar visibilidade às experiências de sua implantação e poder apresentar resultados concretos que revelam melhores condições para gerenciamento dos fatos que podem variar dentro dos serviços de saúde que comecem a fazer uso desta estratégia de cuidado: ou seja, este estudo pretende ser competente para auxiliar nos processos clínicos e de gestão necessários para a implantação da política e das práticas de RD.

O presente trabalho se propõe a esse fim, qual seja, analisar os impactos das ações dos rds na Rede Pública de Saúde de Uberlândia-MG segundo a perspectiva dos trabalhadores dos serviços de saúde, os quais acompanham e conhecem a prática desses novos profissionais da/na rede. Vale dizer que a Secretária Municipal de Saúde desta cidade é uma das pioneiras na criação de Projetos de Escolas de formação de rds e de Consultório de/na Rua, serviços estes que estão em processo de consolidação na rede pública de saúde (Faria, 2014).

\section{Os caminhos dessa investigação}

Essa pesquisa faz parte de um projeto de pesquisa maior que têm como objetivo investigar os impactos da $\mathrm{RD}$ na rede pública de saúde de Uberlândia. O projeto é dividido em três eixos de pesquisas: uma que avalia os impactos da RD segundo a percepção dos próprios rds; outra que avalia os impactos segundo os usuários do serviço; e a nossa, que avalia os impactos de acordo com a perspectiva dos profissionais que compõem a Rede de Saúde e que trabalham, trabalharam e/ou conhecem a atuação dos rds na rede.

A presente pesquisa qualitativa tem objetivos exploratórios e descritivos. Assim, destaca-se que na metodologia qualitativa aplicada à saúde, não se busca analisar o fenômeno em si, mas sim entender seu significado em âmbito pessoal e/ou coletivo. Isto porque, é a partir da significação que o sujeito atribui a um dado fenômeno que a sua relação com o mesmo é determinada e organizada (Turato, 2005).

Diante disso, a coleta de dados desta pesquisa foi realizada por meio de entrevistas semiestruturadas (em anexo) com profissionais que compõem a rede de saúde da cidade de Uberlândia-MG. Isto porque eles acompanham e/ou participam de alguma maneira a implantação e processo de consolidação da política e das práticas de RD e podem vislumbrar seus impactos de um lugar privilegiado, qual seja, dentro da rede propriamente dita, atuando em alguns de seus serviços disponíveis.

A amostra da pesquisa foi definida tendo como ponto de partida um contato direto com os profissionais nos próprios serviços de saúde onde, de alguma forma atuam os rds. Estes profissionais foram convidados a participar voluntariamente, e alguns deles então, se dispuseram a colaborar. No total, foram entrevistados 21 (vinte e um) participantes, em 08 (oito) unidades diferentes. Esclareça-se que para os convites feitos utilizou-se como critério de escolha aqueles profissionais que, atuam ou atuaram de alguma forma em parceria com os rds. Os cargos dos profissionais entrevistados foram variados, tais como, assistentes sociais, enfermeiros, técnicos e auxiliares de enfermagem, agentes comunitários de saúde, psicólogos e auxiliares administrativos.

O contato com os serviços foi feito por intermédio da coordenadora das Escolas de RD da cidade. Todos os entrevistados tomaram conhecimento e assinaram espontaneamente o Termo de Consentimento Livre e Esclarecido, que detalha os procedimentos da entrevista, assegurando o anonimato dos participantes e a entrega de cópia da gravação da entrevista aos mesmos. Já a análise de dados tem como método a Análise de Conteúdo, elaborada por Bardin (2009). Dentre outros, seu objetivo é o de enriquecer as leituras e minimizar as incertezas explicitadas na fala por meio de suas funções heurísticas (tentativa exploratória que visa descobertas e resolução de problemas) e análise sistemática das informações para verificações. 
Em sua aplicação, a Análise de conteúdo é realizada em três etapas: a análise prévia, que consiste em organização, operacionalização e sistematização do material, por meio de formulação de hipóteses, objetivos e leitura flutuante; a análise exploratória - que significa elaborar codificações e categorizações temáticas das informações obtidas e, por último; o tratamento dos resultados obtidos e interpretação por meio de técnicas descritivas de análise. Ou seja, o enfoque desse tipo de análise está na estruturação de operações analíticas, as quais são adaptadas segundo o que se busca estudar. (Bardin, 2009).

Dessa forma, as interpretações e analises dos temas podem ser realizadas, utilizando como recurso para discussão a leitura de arquivos bibliográficos relacionados com o tema de Redução de Danos, o que possibilita maior compreensão do assunto e a disseminação de novos estudos.

Informa-se que essa pesquisa passou pelo Comitê de Ética em Pesquisa com Seres Humanos da Universidade Federal de Uberlândia (Parecer número: 529.171) e contou com apoio do Programa de Saúde Mental e de Atenção em Saúde da Secretaria Municipal de Saúde de Uberlândia/MG para sua efetivação. Vale dizer que esta pesquisa contou com apoio financeiro de bolsa de iniciação científica para discente oriunda do PIBIC/CNPq.

\section{Os impactos do trabalho dos rds de acordo com os profissionais da rede de saúde}

A análise dos dados coletados aponta que os impactos das ações dos rds podem ser divididos em duas categorias compostas por temas que apresentam o conteúdo chave das informações trazidas na fala dos entrevistados. Essa divisão ocorreu devido à percepção de que todos os temas levantados, mesmo com suas singularidades, sempre se enquadravam em uma das duas seguintes categorias: Modificações nas formas de funcionamento dos serviços de saúde, que se traduzia no apoio a outros setores e serviços de saúde ou afins; capacitação dos demais profissionais da rede em relação a atendimentos mais humanizados e não preconceituosos; fortalecimento do trabalho da equipe de saúde; ampliação da atuação dos serviços de saúde no próprio território ocupado pelos usuários de drogas; redução das possibilidades de negligência em relação ao paciente; ampliação de estratégias para o cuidado em saúde nas unidades de saúde. A outra categoria identificada foi: Mudanças na forma com que se estabelecem as relações entre serviços, profissionais e usuários, perceptível em temas abordados pelos entrevistados como o fortalecimento do vínculo do usuário com o serviço de saúde; percepção, por parte dos usuários do serviço, de que há acolhimento e parceria no serviço de saúde; mudanças na perspectiva do paciente em relação ao que é saúde e ao seu tratamento; mudanças nas práticas, ações e comportamento dos usuários de drogas.
Como mencionado, a primeira das categorias refere-se às modificações que ocorreram nas estratégias de atuação e na dinâmica, técnica e logística dos serviços de saúde, visto que, com a atuação dos rds, os serviços de cuidado em saúde disponibilizados em tais serviços foram ampliados. Já a segunda categoria destaca os impactos que ocorreram no modo como os usuários percebem, vinculam-se e situam-se perante os serviços de saúde. Isto porque, segundo os as verbalizações destacadas nas entrevistas desta pesquisa, o trabalho dos rds é baseado em práticas de humanização e parceria, e com isso os usuários do serviço começam a incorporar novas reflexões sobre o que é saúde e sobre as diferentes formas de realização de um tratamento para o uso abusivo e problemático de drogas. Tal constatação, por sua vez, os motiva a buscar esses serviços, ao invés de se afastarem delas com medo de serem tratados com preconceito e, por conseguinte, com desrespeito.

Assim, vale reafirmar que os temas (ou subcategorias) listados como especificidades das duas categorias de resposta encontradas, detalham ainda mais os impactos da ação dos rds.

Categoria 1: Os impactos nas formas de funcionamento dos serviços de saúde

Foi possível observar, a partir da transcrição da fala dos entrevistados, que um primeiro aspecto que caracteriza o impacto das ações dos rds nos serviços de saúde é o apoio que eles exercem a profissionais de outros setores. Esse apoio refere-se ao trabalho que os rds exercem com a finalidade de auxiliar os demais profissionais a lidarem com as demandas que aparecem nos casos por eles atendidos. Sua atuação pode ser tanto como (i) colaborador no atendimento quanto como (ii) facilitador para o aprimoramento e aplicação das práticas relacionadas com a RD. Em outras palavras, os rds aparecem como um suporte técnico na atuação de outros profissionais o que, por consequência, aumenta a eficácia das intervenções daquele serviço de saúde da rede. E, como Brasil (2005) explica, a RD é parte das diretrizes de tratamento estabelecidas pelo Ministério da Saúde, o que significa que é fundamental que os demais profissionais compreendam essa prática e, no caso de acontecerem dificuldades em seus trabalhos, eles podem, com a presença dos rds, fazer reuniões e discutir as atuações a serem implementadas, além de contarem com reforços na hora de agir. Tal assertiva foi obtida a partir de falas como as que seguem abaixo:

...quando o trabalho deles (rds) começou, a gente estava na unidade de baixo, era lá que ficavam meus pacientes, e eu tinha pacientes bem comprometidos, eu tinha uma paciente que era moradora de rua, e eles me ajudaram bastante com essa paciente. Eu pedia para eles localizarem ela, e dar notícia a seu respeito para mãe dela, então eles serviram como um elo para 
a família, e isso confortou muito essa mãe. E o filho dela, adolescente, também se envolveu com drogas, eu pedi a ajuda deles, e eles estavam nesse trabalho. (Entrevista 04 - Agente Comunitário de Saúde).

Sempre fazemos reuniões na RD, na mediação de conflitos, eles sempre estão aqui também pra nos dar apoio. E de uma forma muito interessante eles vieram aqui, fizeram umas reuniões com as agentes de saúde... e agendaram para andar junto com elas focando os principais aspectos do paciente (Entrevista 05 Enfermeiro (a)).

O segundo aspecto identificado foi a colaboração por parte dos rds na capacitação dos demais profissionais da rede em relação a atendimentos mais humanizados e não preconceituosos, devido à percepção de que os rds auxiliam os profissionais - por meio de conversas e atuações em conjunto - a aprimorarem condutas de tratamento que se adequem à singularidade do paciente, combatendo posturas repressivas e de rejeição. Tal forma de atuação acaba promovendo a disseminação de práticas em saúde relacionadas com a reforma psiquiátrica, pois, como Gonçalves e Sena (2001) explicam, quando são estabelecidas práticas de desinstitucionalização, não se espera apenas que as pessoas deixem de manter os pacientes internados em hospitais, mas também que ocorra um resgaste ao respeito e à singularidade dos mesmos.

Eles (rds) já estão caminhando junto com os agentes de saúde até os nossos pacientes para estar mostrando o real objetivo do programa, falando da necessidade que o usuário tem e que nós não estamos em nenhum momento pra ficar apontando ou julgando, mas sim para acolher e abordar as demandas que eles trazem. (Entrevista 05 - Enfermeiro (a)).

Como é possível observar, a verbalização escolhida para ilustração desse tema demonstra que as práticas dos rds contribuem para que os serviços de saúde adotem práticas de cuidado relacionadas com a desospitalização e com a desinstitucionalização. Tal conduta, por sua vez, minimiza a chance de que sejam perpetradas atitudes preconceituosas, violentas e repressivas por parte dos profissionais de saúde, o que está de acordo com as diretrizes de tratamento estabelecidas pelo Ministério da Saúde (Brasil, 2005).

Outro tema abordado em relação ao impacto da ação dos rds no funcionamento dos serviços de saúde diz respeito ao auxílio que os rds dão para a capacitação dos demais profissionais da rede em relação a outras formas de cuidados em saúde. Isto porque, e em virtude do fato de que os rds trabalham com uma lógica de cuidado pautada pelo respeito aos direitos e escolhas do paciente e pela responsabilidade compartilhada entre profissionais, usuários e comunidade em relação aos cuidados em saúde e redução dos danos causados pelo uso de drogas, a concepção do que é um tratamento é ampliada e, assim, eles se tornam aptos a proporcionar outras formas de cuidado até então não utilizadas na rotina de trabalho. Assim os vários profissionais dos serviços acabam por adotar posturas e práticas de RD e essa percepção de que devem existir outras formas de cuidados em saúde mais humanizada acaba atingindo todos que compõem a rede de atenção.

Além do que, no conteúdo das entrevistas, é percebido a necessidade de tais profissionais receberem treinamento qualificado para realizar essas práticas, já que, em suas formações profissionais, apenas foram transmitidos saberes e práticas tradicionais e hegemônicos de tratamento pela via da abstinência e internação.

Com a presença dos rds, esse tipo de aprendizado se torna mais rápido e eficaz, pois eles, por meio de conversas, intervenções em equipe e em reuniões, auxiliam estes profissionais a desenvolverem tais práticas.

A partir disso, tem-se que a política de RD é uma estratégia de cuidado que percebe que os danos resultantes do uso de drogas são mais extensos do que vícios ou desregulações fisiológicas. Assim, as possibilidades para atenção e cuidado aumentam, já que outros elementos passam a ser ponto de preocupação. Tal assertiva vai ao encontro do afirmado por Queiroz (2001), que pontua que a $\mathrm{RD}$ é uma forma de manejo seguro de uma variedade de comportamentos de alto risco e dos danos por eles acometidos.

Por exemplo, eu que sou enfermeira, quando eu estudei lá na faculdade sobre drogas aprendi que não pode!! É proibido, não se deve usar de jeito nenhum. Então isso é o que a gente aprende de drogas né? (...) E de repente chega a redução de danos para gente, e a gente conheceu os redutores de danos. E a gente começou a ter uma outra visão do que que é o uso de drogas e de como a gente ia ajuda esse paciente na redução de drogas. Então sensibilizou muito a gente!! (Entrevista 09 - Enfermeiro (a)).

...a partir do momento que a gente teve a oportunidade de entender mais sobre o trabalho, toda a equipe já começou a enxergar o usuário de outra forma, então assim, já se mobilizaram a fazer grupo: "vamos fazer um grupo para usuário de álcool e outras drogas” para falar um pouquinho sobre sei lá, doenças sexualmente transmissíveis, falar assim sobre outros temas, não que seja abordar álcool e drogas mesmo, para trazer ele assim mais pra unidade sabe... pra acompanhar mais de perto, porque não necessariamente assim ele vai precisar de ajuda psicológica, mas sim clinica, um exame de sangue, ou outro tipo... (Entrevista 11 - Psicólogo (a)).

O fortalecimento da equipe de saúde é outro impacto percebido, pois os rds aparecem com novos conhecimen- 
tos para agregar ao serviço de saúde, com funções próprias e exclusivas. E tal condição serve como uma força a mais para planejar as práticas de tratamento e ampliar as formas de cuidado e intervenção disponíveis.

Assim, é possível destacar que os atendimentos dos rds têm uma perspectiva de cuidado multiprofissional e interdisciplinar, na qual o paciente é atendido por um coletivo de profissionais que articulam múltiplas intervenções técnicas, por meio da comunicação e cooperação (Peduzzi, 2001). Tal forma de atuação garante um atendimento abrangente que consegue perceber demandas biopsicossociais e ajudar a pessoa a reduzir os danos que vivencia em seu dia-a-dia.

E a gente não trabalha tanto com a parte psicológica do paciente, com as outras partes... com os outros danos que pode causar esse problema. Então os redutores de dano vem complementando (Entrevista 09 Enfermeiro (a)).

...nós temos muita tarefa então eles (rds) são uma força auxiliar pra lidar com os pacientes mais especiais. (Entrevista 07 - Agente Comunitário de Saúde).

Outro tema que surgiu nas entrevistas é a ampliação da atuação dos serviços de saúde no próprio território ocupado pelos usuários de drogas. Isto porque, a atuação dos rds não acontece somente no serviço de saúde, mas também na própria casa do paciente e nos denominados "pontos" que os usuários mais frequentam, garantindo assim, uma extensão dos serviços prestados, pois eles atuam em espaços que nenhum outro profissional ocupa.

Por conseguinte, o trabalho dos rds acontece, na maior parte das vezes, em territórios violentos e a melhor maneira de conquistar a confiança das pessoas que ocupam estes locais é por meio de ações relacionadas com o cuidado e com a criação de laços afetivos (Brasil, 2014). Em outras palavras, os rds conseguem formar vínculos com pessoas que dificilmente teriam a oportunidade de se encontrar com profissionais qualificados ou de se vincular a algum serviço de saúde.

...antes não tinha isso, se o paciente estava lá na rua, então a gente nem sabia, tem muitos que chegam aqui por eles e são bem recebidos, seu V. tem o W. tem o A.A., tem... tem vários pacientes que são trazidos pelo consultório de rua, pessoal, redutores de danos, eu acho que sem eles essas pessoas, eles estariam, poderiam ter alguma coisa grave, ou falecido ou... e a gente não ia saber desse cuidado, pessoal da rua. (Entrevista 16 - Técnico em Enfermagem).

E a gente como agente de saúde, acaba fazendo esse trabalho, não intensamente porque a gente não vai lá na "boca”, aonde os rds vão. (Entrevista 04 - Agente Comunitário de Saúde).
Outro tema ou subcategoria constatado foi o de que o trabalho dos rds minimiza as possibilidades de negligência em relação a um paciente. Isto porque, eles conseguem evitar que outros profissionais possam vir a evitar ou mesmo negar tratamento a pacientes do seu território e que são usuários de drogas - algo que costuma acontecer com frequência - devido à dificuldade/impossibilidade que alguns pacientes têm de se "enquadrar" nos modelos e rotinas de trabalho tradicionalmente preconizadas nos serviços de saúde, o que acaba servindo de justificativa para os profissionais que não conseguem atuar respeitando as singularidades de cada caso e, por consequência, desistem de realizar os atendimentos e acabam por responsabilizar o usuário pela falta de oferta de cuidado em saúde.

Então quando o redutor de danos está lá fora, está disposto a ouvir, ele faz a triagem, então ele traz pronto, "quadradinho": "Olha, a dor é no fígado, a dor é aqui na lateral”, ele (o rd) entra dentro da sala do médico, fala onde que é a dor, tutela e quando ele tutela, a consulta fica objetiva e o médico não expulsa o paciente da sala e ele consegue segurar esse excesso de diálogo do paciente e ai a consulta acontece (Entrevista 18 - Assistente Social).

Por outro lado, também encontramos profissionais que "não desistem" do paciente, mas mesmo assim muitas vezes o paciente perde consultas, não segue o tratamento como orientado, etc. De acordo com os relatos, nesse tipo de situação, o rd, muitas vezes, exerce uma espécie de função de suporte ao usuário, acompanhando-o nas consultas, no tratamento proposto, orientando familiares quando houverem. A fala a seguir confirma tal assertiva:

São pacientes que não se predispõem a vir (...) não estão predisposto a um agendamento conforme as normas, conforme a fila, conforme a data que você agenda, conforme o horário que a agenda tá aberta, ele não memoriza isso, eles não se encaixam nessa proposta, ai o redutor de danos dentro da unidade, faz a diferença pra esse tipo de tratamento não intensivo (Entrevista 18 - Assistente Social).

Já o último impacto de ações de rds que altera a dinâmica funcional dos serviços de saúde é a ampliação de estratégias para o cuidado em saúde nas unidades em que atua. As funções dos rds tem sua especificidade e por isso, eles adotam práticas de intervenções ao longo de sua rotina, que respeitam a autonomia e a liberdade dos usuários, possibilitando a aproximação dos serviços de saúde com as práticas concebidas pela reforma psiquiátrica.

Dizemos acima que apenas 20\% dos usuários de drogas conseguem seguir um tratamento pautado na abstinência, o que acaba por inviabilizar o tratamento para os $80 \%$ restantes. Contudo, com a política de $\mathrm{RD}$, outras 
práticas de cuidado em saúde começaram a ganhar espaço e, diversas pessoas que antes não recebiam qualquer tipo de tratamento, passaram a recebê-lo. Desse modo, pode-se destacar que, com o trabalho dos rds, os serviços de saúde ficam mais preparados e capacitados para atender as pessoas. Além do que, se aproximam de um grupo que acredita não possuir lugar socialmente reconhecido no mundo atual. (Lancetti, 2007)

Isso é o que os rds proporcionam que eu acho que outras políticas não proporcionaram, porque é "eu cuido de você, independente do seu desejo" assim né!... e outras políticas tem uma ideia de cidadão perfeito (Entrevista 15 - Psicólogo (a)).

Ele (rd) pensa não só assim, na questão da substancia, "ah quanto o fulano está usando ou deixou de usar", mas pensa nos outros cuidados que ele tem, com a saúde, com o corpo (...) quando o paciente está no uso, ele não vai lembrar de tomar água, de escovar os dentes, de marcar uma consulta no "postinho", não vai, não vai na consulta, e o redutor de danos eu acho que ele pode ir por essa via, assim... (Entrevista 17 - Psicólogo (a)).

...eles (rds) conseguiram reunir principalmente jovens, para fazer algum esporte, para estar numa palestra... (Entrevista 12 - Agente Comunitário de Saúde).

Categoria 2: As mudanças nas relações entre serviços, profissionais e usuários.

O primeiro aspecto observado nessa categoria foi o fortalecimento do vínculo do usuário com o serviço de saúde, devido ao fato de que os rds atuam fazendo a ponte entre o usuário e o serviço de saúde. Em virtude de sua atuação direta no território ocupado pelos usuários, eles acabam por conseguir uma maior proximidade com esse grupo de pessoas e podem construir relações positivas e convidativas no que se refere ao serviço de saúde.

Desse modo, destaca-se que o vínculo estabelecido entre os rds e os usuários aparece como algo muito importante, pois estes são estimulados a procurar os serviços de saúde, sem o temor de serem conduzidos a uma internação, ou tratados com preconceito ou ainda obrigados a fazer o que não desejam. Além do que, como explicam Schrank e Olschowsky (2008), o vínculo é fundamental para a construção de vias menos dolorosas durante a vivência de algum sofrimento.

...eu fiquei com dó de ouvir a assistente social contar (...) às vezes eles (usuários) tem essa dificuldade de se vincular a uma unidade de saúde por medo, por medo de chegar aqui e a gente expulsar, mandar embora sabe... então se esse vínculo que os agente redutores criam é muito importante para a gente, então acho que é um ponto muito positivo. (Entrevista 11 - Psicólogo (a)). ...eles (usuários) aderem muito melhor por causa do vínculo, eles aceitam bem mais, as orientações e o tratamento mesmo, por exemplo, o paciente usuário de álcool e drogas ele tem várias predisposições de outras doenças, tuberculose, HVI, ai a gente conversa melhor com eles, bem melhor, através do pessoal da redução de danos, eles abrem mais essas portas para a gente. (Entrevista 19 - Enfermeiro (a)).

A fala dos entrevistados também nos permitiu a tematização de outro impacto da atuação dos rds de acordo com os profissionais entrevistados, qual seja, usuários do serviço passam a sentir que há acolhimento e parceria nos Serviços de Saúde, dessa forma, os serviços passam a ser reconhecidos como lugares receptivos e propensos à formação de vínculos. Afinal, o trabalho dos rds dialoga com os profissionais a fim de que os mesmos passem a adotar posturas éticas, respeitosas, de proximidade e cuidado, o que possibilita que os usuários percebam a existência de companheirismo e se tornem, por consequência, mais próximos dos rds e dos serviços de saúde.

Assim, os resultados desta pesquisa demonstram que o trabalho dos rds, acrescido de práticas essencialmente humanizadas, resulta na adesão do paciente ao tratamento. E tal fato contribui para a diminuição da quantidade de cidadãos marginalizados pelo sistema de saúde.

...eles (rds) ficavam circulando, os pacientes tinham "muuuita" proximidade com eles, uma relação bem próxima, bem de afeto. (Entrevista 17 - Psicólogo (a)).

...os pacientes gostam muito de estar com eles (rds), gostam muito de trocar ideias, de estar perto, de bater um papo, dessa coisa de ficar perto independe para fazer o que, assim, eu percebo que a galera da $\mathrm{RD}$, nesse sentido consegue isso que eu falei mesmo, se aproximar mais (Entrevista 15 - Psicólogo (a)).

Também foi possível perceber que o trabalho dos rds influencia para que ocorram mudanças na perspectiva do paciente em relação ao que é saúde e ao seu tratamento. Em outras palavras, os próprios usuários do serviço de saúde, suas famílias e a comunidade a qual pertencem, começam a incorporar novas compreensões a respeito de como são os novos tratamentos para esse grupo de pessoas, o que faz proliferar ideias que contribuem para a reconstrução dos paradigmas a respeito dos tratamentos no campo da saúde mental.

...ai um redutor de danos vai lá e conversa, e a gente não precisa ir lá ver se tem algum machucado, fazer um curativo, eles conseguem trazer o usuário, fazer um vínculo entre o usuário e a unidade e isso é muito importante porque vai cuidar da saúde também. (Entrevista 13 - Agente Comunitário de Saúde). 
...uma vez, conversando com um paciente, ele falou que com os redutores de danos ele foi aprendendo muitas coisas na vida dele... aprendendo a se cuidar, aprendendo o que que era felicidade, o que que o uso dele tinha a ver com a vida dele sabe! (Entrevista 17 - Psicólogo (a)).

Por fim, o último tema reconhecido na análise do conteúdo das entrevistas refere-se às mudanças nas práticas, ações e comportamento dos usuários de drogas, que começaram a acontecer após o trabalho dos rds. As falas a seguir transcritas comprovam tal assertiva:

...as coisas acontecem só na casa dela mesmo. Então acho que ela ficou menos agressiva, ficou mais cuidadosa, ela ficou mais cautelosa com as medicações! porque a redução de danos sempre pega muito no pé dela, ela até fala que não vai parar de tomar o medicamento. (Entrevista 09 - Enfermeiro (a))

...tinha uma paciente que já tinham até tentando matar ela uma vez por causa de droga mesmo. E ela não parou de usar, mas ela mudou. Ela está bem agora, continua usando, mas usa outro tipo. Cuida da família agora, na época ela tinha até perdido a guarda dos filhos, atualmente os filhos estão com ela novamente. Então ela não parou, mas teve uma mudança bem positiva. (Entrevista 20 - Agente Comunitário de Saúde).

Assim, nesta última constatação é possível destacar que as ações dos rds parecem conseguir ser efetivas em relação a seus objetivos, na medida em que auxiliam os usuários de drogas a adotarem práticas mais saudáveis e redutoras de danos, mesmo quando optam por viver uma vida fora dos padrões comuns instituídos socialmente.

\section{Considerações finais}

A partir da análise do conteúdo das entrevistas, é possível perceber que os impactos das ações dos rds na rede pública da cidade de Uberlândia-MG estão relacionados com o aumento das potencialidades de atendimento dos serviços de saúde, que passam a revigorar suas técnicas e estratégias para a manutenção do cuidado em saúde, de acordo com uma lógica que segue as diretrizes da Luta Antimanicomal e da Reforma Psiquiátrica. Também ocorrem mudanças na forma pela qual o serviço de saúde é percebido pelos usuários, pois com a $\mathrm{RD}$, inicia-se um processo de incorporação de novas concepções a respeito de como é um tratamento para pessoas que fazem uso abusivo e dependente de drogas.

Entretanto, vale ressaltar que os impactos não ocorrem, necessariamente, na mesma intensidade e frequência em todas as unidades de saúde pesquisadas, pois aspectos particulares de cada um dos entrevistados e serviços influenciam na relação que é construída com os rds. Assim, pode-se considerar que em cada serviço de saúde acontecem impactos diferentes, ou apenas alguns dos descritos nesta pesquisa.

Dessa forma, e em virtude das inevitáveis e constantes variáveis que constituem a realidade e envolvem a atuação do rd nos cuidados à saúde de usuários de drogas, impõe-se que a política de RD tenha uma gestão e acompanhamento com vistas a uma certa uniformidade de ações e consequentemente de seus impactos na rede toda. A partir dessa gestão e acompanhamento longitudinal será possível compreender ainda mais como estão sendo as repercussões da implantação desse tipo de estratégia para o cuidado em saúde e, com isso, aprimorá-la para que os princípios da universalidade e equidade no SUS sejam alcançados.

Vale destacar que os resultados que foram aqui apresentados nos parecem contundentes no que se refere ao impacto exitoso da política de RD e das ações dos rds vistas como boas práticas em saúde e que devem ser almejadas por todos os serviços, a fim de minimizar os danos advindos do uso problemático de drogas.

Com isso, espera-se que o presente trabalho contribua para a produção e consolidação de saberes e práticas exitosas, que proporcionem melhorias na qualidade de vida da população, principalmente daqueles que demandam cuidados em saúde devido ao seu grande sofrimento.

\section{Referências}

Arbex, D. (2013). Holocausto brasileiro. São Paulo, SP: Geração Editorial.

Bardin, L. (2009) Análise de Conteúdo. Lisboa, Portugal; Edições 70, LDA.

Brasil (2001). Ministério da Saúde. Secretaria Executiva. Coordenação Nacional de DST/AIDS. Manual de redução de danos / Ministério da Saúde, Secretaria Executiva, Coordenação Nacional de DST e AIDS. - Brasília: Ministério da Saúde.

Brasil (2005). Portaria $n^{0} 1.028$, de 01 de julho de 2005: Determina as diretrizes que visam à redução de danos sociais e à saúde, decorrentes do uso de produtos, substâncias ou drogas que causem dependência, sejam reguladas por esta Portaria 2005; 01 Jul.

Brasil (2012). Portaria $n^{0} 123$, de 25 de janeiro de 2012: Estabelece a revisão de diretrizes e normas para a organização da Atenção Básica, para a Estratégia Saúde de Família (ESF) e o Programa de Agentes Comunitários de Saúde (PACs). 25 Jan.

Brasil (2014). Ministério da Saúde. Secretaria de Gestão do Trabalho e da Educação na Saúde. Departamento de Gestão da Educação na Saúde. Guia de Saúde Mental: atendimento e intervenção com usuários de álcool e outras drogas /.Fundação Oswaldo Cruz, Grupo Hospitalar Conceição. - Brasília: Ministério da Saúde. 
Faria, F. G. (2014). Os impactos da ação dos agentes redutores de danos na rede de atenção em saúde de Uberlândia/MG sob o ponto de vista deles mesmos. (Trabalho de Conclusão de Curso). Instituto de Psicologia, Universidade Federal de Uberlândia, Uberlândia.

Fonseca, E. M., \& Bastos, F. I. (2005). Política de Redução de Danos em Perspectiva: comparando as experiências americana, britânica e brasileira. In: Acselrad, G. (Org.), Avessos do Prazer: drogas, AIDS e direitos humanos (p. 289-310). Rio de Janeiro, RJ: Editora Fiocruz.

Gonçalves, A. M., \& Sena, R. R. (2001). A reforma psiquiátrica no Brasil: contextualização e reflexos sobre o cuidado com o doente mental na família. Revista Latino-americana de Enfermagem, 9(2), 48-55.

Lancetti, A. (2007). Clínica Peripatética. São Paulo, SP: Hucitec.

Machado, L. V., \& Boarini, M. L. (2013). Políticas sobre drogas no Brasil: a estratégia de redução de danos. Psicologia: Ciência e Profissão, 33(3), 580-595.

Manzini, E. J. (1990) A entrevista na pesquisa social. Didática, São Paulo, 26/27: 149-158.

Pacheco, M. E. A. G. (2013). Política de redução de danos a usuários de substâncias psicoativas: práticas terapêticas no projeto Consultório de Rua em Fortaleza, Ceará (Dissertação de mestrado, Centro de Estudos Sociais Aplicados, Universidade Estadual do Ceará, Fortaleza). Recuperado de http://www.uece.br/politicasuece/dmdocuments/ disserta\%C3\%A7ao_Eniana.pdf.

Queiroz, I. S. (2001). Os programas de redução de danos como espaços de exercício da cidadania dos usuários de drogas. Psicologia: ciência e profissão, 21(4), 2-15.

Passos, E. H., \& Souza, T. P. (2011). Redução de danos e saúde pública: construções alternativas à política global de "guerra às drogas". Psicologia \& Sociedade, 23(1), 154-162.

Peduzzi, M. (2001). Equipe multiprofissional de saúde: conceito e tipologia. Revista Saúde Pública, 35(1), 103-109.

Schrank, G., \& Olschowsky, A. (2008). O centro de atenção psicossocial e as estratégias para inserção da família. Revista Escola de Enfermagem, 42(1), 127-134.

Sodelli, M. (2010) A abordagem proibicionista em desconstrução: compreensão fenomenológica existencial do uso de drogas. Ciencia e Saúde Coletiva, 15(3): 637-644, 2010 .

Souza, J., Kantorsi, L. P., Gonçalves, S. E., Mielke, F. B., \& Guadalupe, D. B. (2007). Centro de atenção psicossocial álcool e drogas e redução de danos: novas propostas, novos desafios. Revista de Enfermagem, 15(2), 210-217.

Turato, E. R. (2005). Métodos qualitativos e quantitativos na área da saúde: definições, diferenças e seus objetos de pesquisa. Revista de Saúde Pública, 39(3): 507-514.
Ricardo Wagner Machado da Silveira - Graduado em Psicologia pela Universidade Federal de Uberlândia, Mestre e Doutor em Psicologia Clínica (Núcleo de Estudos e Pesquisas da Subjetividade) da Pontifícia Universidade Católica de São Paulo. Docente da Universidade Federal de Uberlândia. Endereço Institucional: Av. Pará, no 1720, Campus Umuarama, Bloco 2C, sala 34, CEP: 38.401-136. Uberlândia - MG. Email: ricardo.silveira@ufu.br

Paulo Otávio Andrade Oliveira D’Tôlis - Graduado em Psicologia pela Universidade Federal de Uberlândia/MG.

Recebido em 23.01.2016 Primeira Decisão Editorial em 03.03.2016 Aceito em 02.04.2016 